\title{
Hebe Uhart (1936-2018)
}

\section{( Pía Bouzas}

Escritora

El departamento de la calle Acuña de Figueroa donde Hebe vivió a lo largo de treinta años tenía dos características centrales: un balcón en "ele" que miraba al este y al norte, a las calles Acuña y Potosí, respectivamente, y una vista abierta de todo el cielo de Almagro. Es decir, el sol pegaba todo el día. Era el último piso del edificio, pero eso no importaba (el exceso de calor o de frío era algo que podía mantenerse a raya con artefactos prácticos). Era modesto, manejable, con lo indispensable para una vida sencilla y práctica; conceptos todos centrales en ella: un living para trabajar y dar talleres, un dormitorio, y un extenso balcón con hiedra, plantas trepadoras varias, macetas pequeñas o grandes, de conjunto inarmónico, y una parrilla para ofrecer asados a los amigos.

Si tuviera que buscar una escuela para un chico, me dijo un día, me fijaría que tuviera mucho sol, nada más. Me miró sin insistencias, como era su estilo, pero muy segura de su afirmación. Yo estaba por entonces buscando un jardín de infantes para mi hijo y me parecía que debía ofrecer la quintaesencia de algo indefinible. Al sol se crece, se pastorea, se piensa, se juega, podría haber explicado. Se conversa. Al sol se vive. Hebe fue maestra y directora de escuela primaria, docente en el Colegio Nacional Buenos Aires por un breve y angustioso tiempo, docente universitaria en la cátedra de Filosofía de Tomás Abraham en el CBC de la UBA y también en la Universidad de Lomas de Zamora durante más de veinte años. Y maestra, por supuesto, de talleres de escritura desde fines de los años ochenta. Si algún día perdiera la memoria o sufriera de esas enfermedades irreversibles, pediría que me dejaran siempre al sol, como los animalitos. Eso también me dijo.

Al balcón se accedía desde el dormitorio y desde el living. Como realmente era un balcón muy largo, Hebe se animó a hacer, en uno de los extremos, un cerramiento que permitiera pasar del dormitorio a una suerte de escritorio: puso allí una mesa, una silla, y uno de esos muebles multiuso comprados en Easy o en alguna mueblería del barrio. Lo usó un tiempo, me dijo, no le sirvió. Se sentía demasiado expuesta a la mirada de los vecinos, demasiado observada cuando trabajaba allí. Lo abandonó. Observar sin ser observada, escribir sin quedar adherida a la figura de escritor, escuchar sin interferir demasiado, era su manera de proveerse de materiales para su escritura: gestos, relatos de vida, formas de decir. La atención, como aprendió con Simone Weil, es un acto de humildad y entrega, hay que mirar hasta que de los objetos salga la luz. Mirar sin interpretar, o en todo caso, hacer de ese movimiento imaginario, pura escritura. Pero diría, además, algo bastante obvio: la contigüidad del dormitorio 
no era productiva en su literatura. Cuando la conocí, a fines de los noventa, ya no lo usaba. Escribía en la mesa del living o en cafés del barrio. El living daba de frente al cielo abierto de Almagro, los cafés la metían de lleno en la vida urbana o semiurbana, en el corazón de los pueblos que visitaba: "A mí me gusta la naturaleza, pero un rato. Un café, sí, un café tiene que haber. Yo me voy al café y converso".

La casa tuvo algunas remodelaciones sencillas a lo largo de los años: un aire acondicionado para poder estar en el verano, nuevos muebles de cocina que reemplazaran la fórmica naranja tan años setenta, y la más importante, o la que le dio más alegría, fue la expansión de la cocina sobre el balcón, en el otro extremo de la "ele". Esta vez ya no era un cerramiento sino una obra completa: extensión de pared, con dos ventanas, una que diera a la calle Potosí, otra que diera al balcón, y trasposición de pileta de lavadero (del exterior al interior). Cualquiera hubiera pensado que allí haría una extensión de las funciones domésticas básicas asociadas a la cocina (lavar o cocinar), sin embargo no fue así: instaló un segundo escritorio. Una mesa alta de madera de pino bajo la ventana que miraba al balcón y una cómoda silla de oficina confirmaron lo que era rarísimo. Hebe se había construido un escritorio aéreo, y por lo tanto ligero: le bastaba un cuaderno liso para escribir sus historias, dos o tres libros que estuviera leyendo, y unos fibrones gruesos, preferentemente negros. Un atado de cigarrillos, el cenicero de metal. Eso era todo lo que se veía en su mesa. Recibía el sol de la mañana, la vista de sus plantas, el cielo, las transversales entre edificios.

A Hebe, como ella misma dijo muchas veces, le gustaba viajar y le gustaba volver a casa. De curiosidad inagotable, desde muy joven cargó valijas y mochilas: Ushuaia, Bolivia, Brasil, más adelante Europa. Viajar y escribir siempre estuvieron estrechamente ligados. Ya en sus primeros libros aparecen la observación del viaje y el relato de tono autobiográfico. Hebe es autora de una extensa y singular obra narrativa conformada por varios libros de cuentos, novelas cortas y crónicas de viaje, que se inició en 1962 con Dios, San Pedro y las almas, y concluyó en 2017, con la publicación de su libro de crónicas Animales. Es difícil calibrar la originalidad de su trabajo, una escritura que arma sus tradiciones por fuera de las líneas centrales de la literatura argentina: del siglo XIX prefiere a Mansilla, a Fray Mocho, a Wilde; del siglo XX no duda y cruza a Uruguay: elige a Felisberto Hernández como faro, como maestro: un escritor de entrecasa, como le gustaba decir.

A fines de los noventa había conseguido que le pagaran para viajar y escribir. Así recorrió muchas ciudades de Uruguay y del interior del país. En muchos casos, volvía del viaje y escribía una crónica y un cuento, en tándem. Encabalgada en los dos géneros, los distinguía apenas por la escritura más inmediata o más reposada; más documentada, más ficcionada. En los últimos diez años, sin embargo, se volcaría de lleno a la crónica de viajes y a recorrer con energía incansable todo el país y Latinoamérica. Decía a quien quisiera escuchar que la realidad era mucho más variada que su imaginación. El viaje aparecía como una posibilidad de no repetirse a sí misma, de estar con la vida en movimiento, de estar bajo el sol. Viajaba, escribía, vivía, y viceversa.

En diciembre del año pasado, con Eduardo Muslip fuimos varias veces al departamento de Acuña de Figueroa: estaban allí sus libros y sus papeles, su biblioteca. Nos llamó la atención al revisar su biblioteca la fidelidad a un núcleo duro de intereses a lo largo de tantos años. Hebe había resuelto lo que suele ser un problema para cualquier escritor: lectora incansable y curiosa, mantenía a raya sin embargo su biblioteca física. Estaba al tanto de la escritura de los más jóvenes y de mucho de lo que corría por canales no convencionales (no necesariamente moderno), pero se desprendía rápidamente de aquello que ya no volvería a leer: regalaba, armaba pilas de libros que se llevaban sus talleristas. En tantos años nunca la vi agregar estantes o comprar muebles para expandir su biblioteca. Como a la hiedra, como a todas sus plantas, 
la hacía más fuerte quitando las hojas muertas. Su biblioteca apenas constaba de seis o siete estantes organizados según temáticas o países: animales, cronistas, viajeros, indígenas, todo aquello que iba nutriéndola para su escritura. Chile, Ecuador, Brasil, Italia. Y en los estantes superiores sus libros de filosofía. Spinoza, Kierkegaard, Nietzsche, Simone Weil: lecturas formativas y fundantes de su mirada, del asombro, de la fascinación por la hendidura entre palabra y sentido, entre voluntad y deseo, entre decisión y acción. Hendidura que exploraría con humor y con equilibrio chejoviano.

Curiosamente para alguien que hacía gala de echar lastre, Hebe conservó en dos cajas las libretas y cuadernos variopintos donde tomaba notas, preparaba sus clases, escribía primeras versiones de sus libros de cuentos. Libretas en las que se funden, se mezclan, se yuxtaponen como en un remolino las múltiples lecturas, la experiencia cotidiana (nunca en estado confesional) y los proyectos de escritura. Hay materiales de sus clases de filosofía del CBC: apuntes que se dirigen a la clase pero que al mismo tiempo hablan de sus intereses de escritura. Por ejemplo: "Hume: Del orgullo y la humildad en los animales" o diálogos filosófico-extremos sobre el análisis de la idea de causa, aspecto central en toda narración: "El calor dilata los cuerpos. ¿Por qué? Porque tiene el poder o la energía para hacerlo. ¿Por qué? No sé.”. Final abrupto, como el de sus charlas telefónicas con un "chau" siempre imprevisto. Como si en ese final abrupto apareciera el límite de todo saber, de toda comunicación posible, de todo encuentro. Y entonces pasa a otra serie. Los mitos griegos: Prometeo, Casandra, el origen de la tragedia, y luego Kafka, Flannery O'Connor, Chéjov, Natalia Ginzburg, Spinoza. Y así.

En las libretas aparecen entremezcladas listas de actividades cotidianas. Por ejemplo, esta:

Febrero: 1. Héctor, cortina y toldos, 2. Llamar a España e ir a la editorial, 3. Contestador y control. 4. Fin de mes, horarios de taller 5. Terminar y pasar "El holandés errante", 7. Visita animal y veneno de hormigas. 8. Peluquería y depilación.

La lista citada está en el cuaderno donde escribió algunos de los cuentos de lo que sería el libro Del cielo a casa. Es un cuaderno barato de hojas lisas y tapa blanda, con dibujos de animales marinos en la portada: una ballena, una tortuga de agua, algas. Los textos originales están escritos en la hoja derecha. En las hojas de la izquierda, en el reverso, hace anotaciones, observaciones de escritura. Detalles que agregar, exploraciones del lenguaje. Momentos de una segunda escritura, comentarios sobreimpresos. Allí aparece otra vez Hume, más sobre los animales y las formas de hablar de un personaje: "Me decían madrina y entendía madera", "Amaba las palabras, ¿cuáles? Muy "jorobado" y después lo aplicaba a cualquier cosa; un día muy jorobado, el pan está jorobado, la calle está jorobada". A veces condensa las unidades narrativas. Hay también textos que no cuajaron (como decía ella), por ejemplo "Huésped" que comienza así: "Tengo una gata hospedada en mi departamento y le puse Catalina; la dueña la llama Catalina y también Tile, porque tiene ojos de corista y se mueve como tal. Yo prefiero llamarla Catalina porque responde a una persona de trabajo y ella es gran emprendedora: desenchufa la computadora, quiere tomar mate, sacar los cigarrillos del cenicero para jugar[...]". Hebe pensaba mucho los textos, pero escribía rápido, sin demasiadas correcciones posteriores. Si sale, queda; si no, se tira.

Este cuaderno de repente adquiere para mí una importancia mayor. En relación con Hebe, creo que la publicación de Del cielo a casa inauguró lo que sería una etapa insólitamente productiva, un viraje hacia la crónica de viajes (aunque sin abandonar del todo los cuentos) con un enorme reconocimiento de instituciones, premios y público que no había disfrutado antes. En ese aspecto, es un libro bisagra. En lo personal, yo hacía taller con ella por esos años y recuerdo haber escuchado una tarde de febrero la versión inconclusa de "El holandés errante", la que figura allí. Tiene que haber 
sido febrero del 2000 o del 2001. Aunque hacía calor tomábamos café -café y gaseosa, usualmente Paso de los Toros. Serían cerca de las seis de la tarde, y como siempre que yo la visitaba, le pregunté qué estaba escribiendo. Me leyó entonces gran parte del cuento, lo que tenía escrito. “¿Te gustó?", me preguntó. Y se puso de pie, fue hasta el umbral de la cocina, volvió al lado del ventanal, se quedó dando pasos cortos, en vaivén, como siempre hacía. "No quiero terminarlo", dijo y me sonrió con picardía, como si la felicidad de escribir fuera siempre una felicidad primera, una felicidad que sorprende y da pudor confesar, una felicidad que no se quiere soltar.

Quizás por algo de esa escena (por mucho de esa escena) este es uno de los textos que más trabajo me ha costado escribir. Borroneado y vuelto a borronear, sobreabunda o se distiende, pierde forma. Y entonces, me entrego, no puede concluir, apenas interrumpirse. Apenas puedo reiterar la escena de nuestra conversación, del atardecer naranja, el café, el aire de verano, el balcón abierto en el departamento de la calle Acuña. Para que reverbere. Siempre.

Creo que a Hebe este final le hubiera gustado. 